\title{
Downregulated ZNF132 predicts unfavorable outcomes in breast Cancer via Hypermethylation modification
}

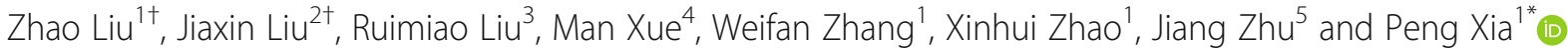

\begin{abstract}
Background: An important mechanism that promoter methylation-mediated gene silencing for gene inactivation is identified in human tumorigenesis. Methylated genes have been found in breast cancer (BC) and beneficial biomarkers for early diagnosis. Prognostic assessment of breast cancer remain little known. Zinc finger protein 132 (ZNF132) is downregulated by promoter methylation in prostate cancer and esophageal squamous cell carcinoma. However, no study provides information on the status of ZNF132, analyzes diagnosis and prognostic significance of ZNF132 in BC.

Methods: In the present study, the expression of ZNF132 mRNA and protein level was determined based on the Cancer Genome Atlas (TCGA) RNA-Seq database and clinical samples analysis and multiple cancer cell lines verification. $P$ rognostic significance of ZNF132 in BC was assessed using the Kaplan-Meier plotter. Molecular mechanisms exploration of ZNF132 in BC was performed using the multiple bioinformatic tools. Hypermethylated status of ZNF132 in BC cell lines was confirmed via Methylation specific polymerase chain reaction (MSP) analysis.

Results: The expression of ZNF132 both the mRNA and protein levels was downregulated in BC tissues. These results were obtained based on TCGA database and clinical sample analysis. Survival analysis from the Kaplan-Meier plotter revealed that the lower level of ZNF132 was associated with a shorter Relapse Free Survival (RFS) time. Receiver operating characteristic curve (ROC) of 0.887 confirmed ZNF132 had powerful sensitivity and specificity to distinguish between BC and adjacent normal tissues. Bioinformatic analysis showed that 6\% ((58/960)) alterations of ZNF132 were identified from cBioPortal. ZNF132 participated in multiple biological pathways based on the Gene Set Enrichment Analysis (GSEA) database including the regulation of cell cycle and glycolysis. Finally, MSP analysis demonstrated that ZNF132 was hypermethylated in a panel of breast cancer cell lines and 5-aza-2'-deoxycytidine (5-Aza-dC) treatment restored ZNF132 expression in partial cell lines.
\end{abstract}

Conclusions: Results revealed that hypermethylation of ZNF132 contributed to its downregulated expression and could be identified as a new diagnostic and prognostic marker in BC.

Keywords: ZNF132, Breast cancer, Bioinformatic, Methylation, Diagnosis, Prognosis

\footnotetext{
* Correspondence: peng_xia666@126.com

${ }^{\dagger}$ Zhao Liu and Jiaxin Liu contributed equally to this work.

'Department of Surgical Oncology, The First Affiliated Hospital of Xi'an Jiaotong University College of Medicine, Xi'an 710061, Shaanxi, China

Full list of author information is available at the end of the article
}

(c) The Author(s). 2021 Open Access This article is licensed under a Creative Commons Attribution 4.0 International License, which permits use, sharing, adaptation, distribution and reproduction in any medium or format, as long as you give appropriate credit to the original author(s) and the source, provide a link to the Creative Commons licence, and indicate if changes were made. The images or other third party material in this article are included in the article's Creative Commons licence, unless indicated otherwise in a credit line to the material. If material is not included in the article's Creative Commons licence and your intended use is not permitted by statutory regulation or exceeds the permitted use, you will need to obtain permission directly from the copyright holder. To view a copy of this licence, visit http://creativecommons.org/licenses/by/4.0/ The Creative Commons Public Domain Dedication waiver (http://creativecommons.org/publicdomain/zero/1.0/) applies to the data made available in this article, unless otherwise stated in a credit line to the data. 


\section{Background}

Breast cancer (BC) is one of the most frequent malignant tumors in females and the fifth leading cause of cancer-associated mortality in worldwide [1, 2]. Advancement in early detection and treatment has improved 5 year-survival rates of $\mathrm{BC}$ patients [3-8]. In 2018 , approximately $62 \%$ of patients with no distant metastasis were diagnosed who displayed a favorable 5-year survival rate of 99\% [9]. However, the 5-year survival rate of the patients with distant metastases decreases to $23 \%$ [10]. Therefore, early diagnosis and treatment improves survival time for BC patients.

Multiple mechanisms have been reported for breast carcinogenesis. These multiple mechanisms include: overactivation of oncogenes, overexpression of growth factors and receptors, and the silence of tumor suppressor [11-13]. Studies have confirmed that epigenetic alterations are involved in tumor progression [12, 14]. Aberrant DNA methylation of $\mathrm{CpG}$ islands is considered to be a vital mechanism to silence anti-tumor genes $[15,16]$. Promoter methylation is an important marker of tumor cells. This is due to its role in tumor cell differentiation, proliferationand survival [17, 18]. Studies have identified a broad range of genes silenced by DNA hypermethylation in carcinogenic process [19]. However, aberrant DNA methylation inactivation of genes related tumor occurrence and development has not been well studied in BC. Zinc finger proteins are an important member of transcription factor family which play a vital role in human diseases including cancers [20]. Majority of zinc finger proteins contain Kruppel associated box (KRAB) domains. KRAB domains induce inhibition of the transcription of downstream genes [21]. Zinc Finger Protein 132 (ZNF132) is located at chromosome 19q13.4 and belongs to the zinc finger protein family. Low expression of ZNF132 has been reported in cancer and is associated with the cell growth, migration and invasiona ablity in prostate cancer and esophageal squamous cell carcinoma up to date. However, its role in $\mathrm{BC}$ remains unknown.

The study investigated the expression and clinical significance of ZNF132 based on the TCGA database and clinical samples analysis. Moreover, further exploration was performed to assess the status of ZNF132 in BC using multiple bioinformatics tools. The epigenetic alteration of ZNF132 was associated with its downregulated expression. Collectively, study findings demonstrated ZNF132 could be a new potential prognostic factor for $\mathrm{BC}$ and may serve as a promising therapeutic target for $\mathrm{BC}$ patients.

\section{Methods}

Analysis of the mRNA expression of the ZNF132 in multiple platforms

The mRNA expression of ZNF132 was explored among the tumor and normal tissues in the BC data of TCGA (http://cancergenome.nih.gov/) [22]. Meanwhile, ZNF132 expression and clinical outcome datas were also obtained from the Oncomine ${ }^{\mathrm{rm}}$ database (www. oncomine.org) [23] and UALCAN platform (http:// ualcan.path. uab.edu/) [24]. Furthermore, the mRNA expression of ZNF132, along with other clinic-pathological data, was downloaded from the Xena platform (https:// xenabrowser.net/).

\section{Clinical samples}

Nineteen pairs of clinical samples including BC and normal adjacent tissues were collected from the First Affiliated Hospital of Xi'an Jiaotong University from January 2019 to March 2019. These patients did not receive any therapeutic intervention and signed an informed consent before surgery. All patients were finally histologically diagnosed by two pathologists based on World Health Organization (WHO) criteria. Ethical approval was provided by the First Affiliated Hospital of Xi'an Jiaotong University Ethics committee.

\section{RNA extraction and quantitative RT-PCR}

RNA was extracted according to a previous protocol [25]. qRT-PCR was performed using the Bio-Rad CFX Manager detection system to assess the mRNA expression of ZNF132 between BC and normal tissues. The SYBR protocol followed the parameters: $95^{\circ} \mathrm{C}$ for $30 \mathrm{~s}$, 38 cycles of $5 \mathrm{~s}$ at $95^{\circ} \mathrm{C}$ and $30 \mathrm{~s}$ at $55^{\circ} \mathrm{C}$. The primers used are as follow: ZNF132: forward: $5^{\prime}$-CCACAGTG TGATGCTGGAAAA CC-3', reverse: 5'-GCTTTC TTGGTGGAAGGATCTGC-3' and $18 \mathrm{~s}$ rRNA: forward: 5' -CGCCGCTAGAGGTGAAATTC-3', reverse: 5' CTTTCGCTCTGGTCCGTCTT-3'. The mRNA expression of the ZNF132 was normalized to $18 \mathrm{~S}$ rRNA cDNA.

\section{Immunohistochemistry (IHC)}

$\mathrm{BC}$ tissues were fixed in $4 \%$ formaldehyde at room temperature for $48 \mathrm{~h}$ in preparation. The ZNF132 antibody (BIOSS, Beijing, China; cat. no. bs-7150R, 1:200 dilution) was used for IHC detection. After incubation overnight at $4{ }^{\circ} \mathrm{C}$, the analysis of ZNF132 staining in BC tissues was performed by two pathologists independently. The staining intensity was defined according to the following criteria: negative, weak, moderate or strong intensity.

\section{Cell lines and drug treatments}

Human breast cancer cell lines MDA-MB-231, MCF7, MDA-MB-453, HCC1937, T47D and DU4475 were used. All cell lines in this study were authenticated by STR analysis in Genesky Co.Ltd. (Shanghai, China) and were excluded the mycoplasma contamination using One-step Quickcolor Mycoplasma Detection Kit (Shanghai Yise Medical Technology Co., Ltd). Cells were 
cultured in suitable medium with $10 \% \mathrm{FBS}$ at $37^{\circ} \mathrm{C}$ with $5 \% \mathrm{CO} 2$ concentration. Assumption that 5-aza-2'-deoxycytidine (5-Aza-dC), DNA methyltransferase (DNMT) inhibitor, restores the expression of ZNF132 both mRNA and protein level is yet to be proved. Therefore, the test groups were treated with $5 \mu \mathrm{M} 5$-Aza-dC (Sigma-Aldrich) and control groups were treated with the vehicle. When the cell density was up to $80 \%$, RNA was extracted using TRIzol ${ }^{\circ}$ protocol. qRT-PCR was performed using the Bio-Rad CFX Manager detection system based on the previous description.

\section{Diagnostic and prognostic significance}

Clinic-pathological datas from TCGA dataset were divided into different subgroups according to Age $(\geq 60$ /<60 years), Her2 (Positive/Negative), ER (Positive/ Negative), PR (Positive/Negative), Tumor size (T2-4/ T1), Lymph node metastasis (Yes/No), Distant metastasis (Yes/No), Clinical stage (II-IV/I) and Expression of ZNF132 (High/Low). Cox proportional hazard regression models were utilized to detect the correlation between these factors and the prognosis of patients with BC. The Kaplan-Meier plotter (http://kmplot.com/) was used to assess the prognosis value of ZNF132 in BC patients including Relapse Free Survival (RFS) and Overall Survival (OS). Furthermore, a reciever operating characteristic curve (ROC) was plotted to determine the ability of ZNF132 expression in distinguishing the difference between BC tissues $(n=1104)$ and adjacent non-tumor tissues $(n=114)$.

\section{Bioinformatic and DNA methylation analysis}

ZNF132 genetic alteration and its impact on the prognosis of BC patients were explored using the cBioPortal OncoPrint (http://www.cBioPortal.org/index.do). Gene Set Enrichment Analysis (http://www.linkedomics.org/) [26] was used to predict potentially biological processes and pathways. In addition, DNA methyltransferases (DNMTs) 1, 3A and 3B and ZNF132 methylation expression including different methylation sites between the BC $(n=790)$ and normal adjacent samples $(n=98)$ from the TCGA database were evaluated to identify the downregulated mechanisms of ZNF132 in BC. Median value of ZNF132 levels was used to divide BC patients $(n=1104)$ into ZNF132 ${ }^{\text {high }}$ and ZNF132 ${ }^{\text {low }}$ subgroups. The methylation level of ZNF132 verified by MethHC (http://methhc.mbc.nctu.edu.tw/php/index.php). The relationship between the methylation level of different CpG island sites and gene expression was explored by correlation analysis.

\section{DNA preparation}

Human breast cancer cell lines were routinely cultured in RPMI 1640 or DMEM medium with $10 \%$ FBS at $37^{\circ} \mathrm{C}$. When the cell density is about $80 \%$, genomic DNA was extracted from 6 breast cancer cell lines. Briefly, cells were lysed with $1 \%$ sodium dodecyl sulfate (SDS) and $0.5 \mathrm{mg} / \mathrm{ml}$ proteinase $\mathrm{K}$ at $48^{\circ} \mathrm{C}$ for $24 \mathrm{~h}$. DNA was subsequently extracted by standard phenol/ chloroform protocol, and dissolved in TE buffer, subsequently stored at $-80^{\circ} \mathrm{C}$.

\section{Sodium bisulfite treatment}

A mixture of $4 \mu \mathrm{g}$ genomic DNA, $10 \mu \mathrm{g}$ salmon sperm DNA and $0.3 \mathrm{M} \mathrm{NaOH}$ was collected. Water was used to top up the final volume to $20 \mu$ l. The mixture was incubated at $50{ }^{\circ} \mathrm{C}$ for $20 \mathrm{~min}$ to denature the DNA. Next, the mixture was transferred into $500 \mu \mathrm{l}$ of solution containing $3 \mathrm{M}$ sodium bisulfite (Sigma, Saint Louis, MO) and $10 \mathrm{mM}$ hydroquinone (Sigma, Saint Louis, MO) and incubated at $70^{\circ} \mathrm{C}$ for $4 \mathrm{~h}$. DNA was then purified using the Wizard DNA Clean-Up System (Promega Corp., Madison, WI). After purification, DNA was followed by ethanol precipitation, dry and dissovled in distilled water.

\section{Methylation-specific PCR (MSP) assay}

Prepare a final $20 \mu \mathrm{l}$ reaction mixture including $50 \mathrm{ng}$ bisulfite-treated DNA, $16.6 \mathrm{mM}$ ammonium sulfate, 67 $\mathrm{mM}$ Tris (pH 8.8), $2 \mathrm{mM} \mathrm{MgCl} 2,200 \mu \mathrm{M}$ dNTP, $200 \mathrm{nM}$ primers, and $0.5 \mathrm{U}$ platinum Taq DNA polymerase (Invitrogen Technologies, Inc., CA). The PCR procedure was as follows: $4 \mathrm{~min}$ denaturation at $95^{\circ} \mathrm{C}$, then $45 \mathrm{~s}$ denaturation at $95^{\circ} \mathrm{C}, 45 \mathrm{~s}$ anneal at $55^{\circ} \mathrm{C}$ and $45 \mathrm{~s}$ extension at $72^{\circ} \mathrm{C}$. This step was repeated for 35 cycles and finally there was an extension at $72{ }^{\circ} \mathrm{C}$ for $5 \mathrm{~min}$. The reaction products were presented in sed on a $1.2 \%$ agarose gel and visualized under UV illumination using an ethidium bromide stain along with a positive control and negative control. The primers used are as follow: methylation forward primer: 5'-GTGTAGGGATCGTTATCGC-3', methylation reverse primer: 5'-AAACGCGTAAC GCTA ACTC-3' and unmethylation forward primer: $5^{\prime}$-TGGGTG TAGGGATTGTTATTGT-3', unmethylation reverse primer: 5' -CATAACACTAACTCCACTTTCAAA-3'.

\section{Western blot analysis}

Cellular proteins including MCF10A, MDA-MB-231, MCF7, MDA-MB-453, HCC1937, T47D and DU4475 was extracted by the previous description. Anti-ZNF132 antibody (1:2000 dilution) were purchased from BIOSS. Inc. Anti-GAPDH antibody (1:40000 dilution) was purchased from Abgent. Inc. the protein bands were visualized using Western Bright ECL detection system (Advansta, CA). 
DNA methylation and clinical characteristics analysis The DNA methylation of ZNF132 and clinical characteristics in TCGA was analyzed by MethSurv (https://biit. cs.ut.ee/methsurv/) [27]. The prognostic values and expression levels of CpG methylation in ZNF132 were explored.

\section{Statistical analysis}

All statistical analyses were performed using SPSS 18.0 (IBM Corp., Armonk, NY, USA) and Graphpad Prism 5.0 software. The association between ZNF132 expression and clinical characteristics was analyzed using the Chi-square test. Univariate and multivariate analyses based on the COX regression model were performed to detect the association between clinical variables and the prognosis of $\mathrm{BC}$. Moreover, the ROC curve was used to evaluate the diagnostic capability between BC and adjacent normal tissue. Student's t-test was used to assess methylation differences of CpG island sites between $\mathrm{BC}$ and adjacent normal tissue. $P$-value $<0.05$ was considered to indicate a statistically significant difference.

\section{Results}

Expression of ZNF132 is downregulated in BC

We first examined mRNA expression of ZNF132 in $\mathrm{BC}$ and adjacent noncancerous tissues using TCGA database and Oncomine database. As shown in Fig. 1a and b, ZNF132 was significantly downregulated in BC compared with normal control. The same trend was obtained in different types of breast cancer using UALCAN platform (Fig. 1c). This finding was further supported using the qRT-PCR (Fig. 1d) and immunohistochemical analysis (Fig. 1e). The protein levels of ZNF132 in breast cancer cell lines and normal breast epithelial cell line MCF-10A were examined. The result showed a moderate or slight decrease in MCF7 and HCC1937 cells as compared to MCF-10A. Finally,

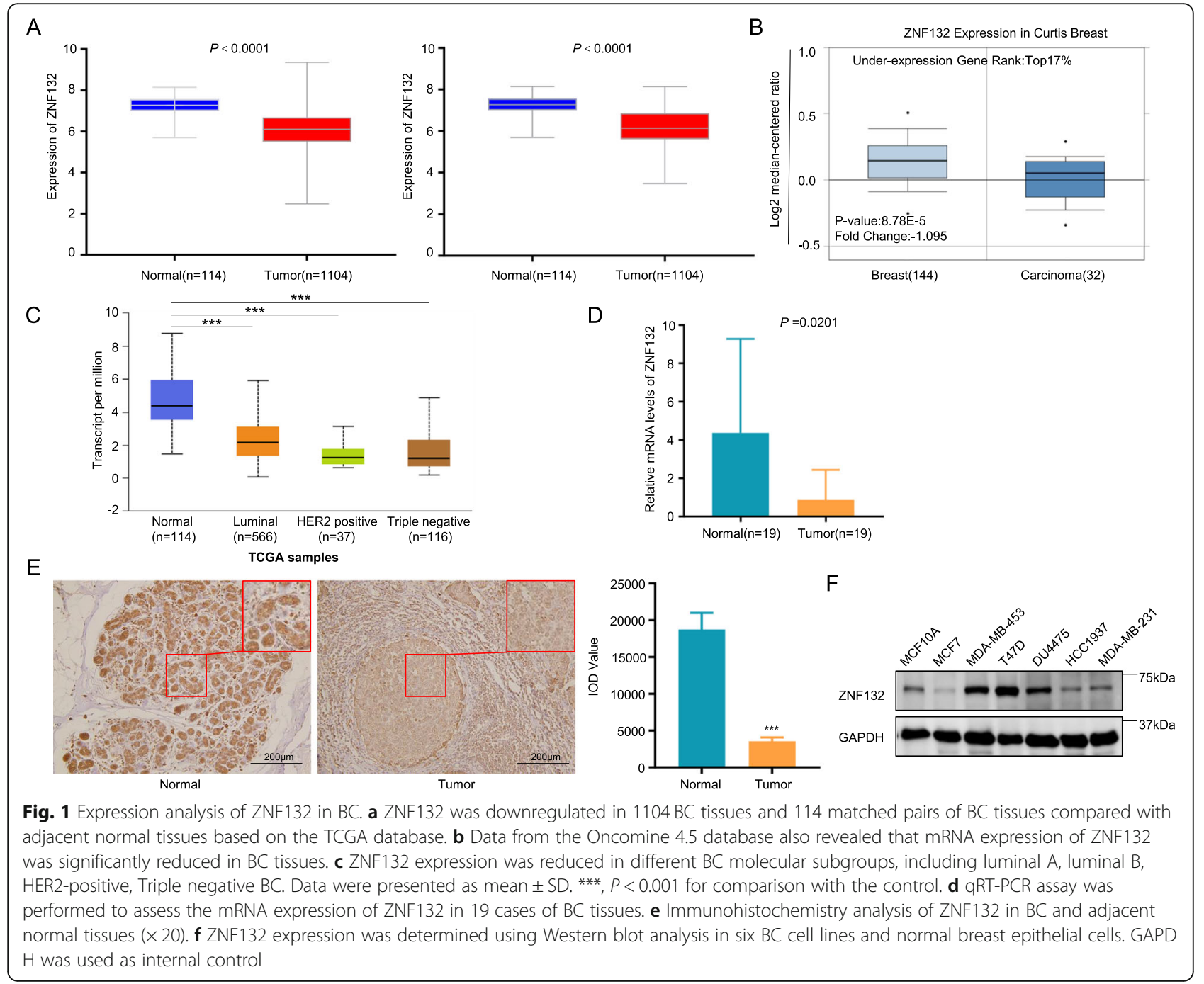


Table 1 Clinical association between ZNF132 expression and clinicopathological variables in BC patients

\begin{tabular}{|c|c|c|c|c|c|c|}
\hline \multirow[b]{2}{*}{ Variable } & \multirow[b]{2}{*}{ Number } & \multicolumn{2}{|c|}{ ZNF132 expression } & \multirow{2}{*}{$\begin{array}{l}X^{2} \text { test } \\
P \text { - value }\end{array}$} & \multicolumn{2}{|c|}{ Correlation } \\
\hline & & Low & High & & $r$ & $P$-value \\
\hline \multicolumn{7}{|l|}{ Age } \\
\hline$\leq 60$ & 611 & 289 & 321 & 0.053 & -0.046 & 0.123 \\
\hline$>60$ & 493 & 263 & 231 & & & \\
\hline \multicolumn{7}{|l|}{ HER2 } \\
\hline Negative & 652 & 292 & 360 & 0.001 & -0.135 & 0.000 \\
\hline Positive & 114 & 70 & 44 & & & \\
\hline \multicolumn{7}{|l|}{ ER } \\
\hline Negative & 179 & 111 & 68 & 0.000 & 0.209 & 0.000 \\
\hline Positive & 601 & 266 & 335 & & & \\
\hline \multicolumn{7}{|l|}{$P R$} \\
\hline Negative & 255 & 157 & 98 & 0.000 & 0.236 & 0.000 \\
\hline Positive & 522 & 216 & 306 & & & \\
\hline \multicolumn{7}{|l|}{ Tumor size } \\
\hline $\mathrm{T} 1$ & 282 & 121 & 161 & 0.006 & -0.125 & 0.000 \\
\hline $\mathrm{T} 2-\mathrm{T} 4$ & 819 & 429 & 390 & & & \\
\hline \multicolumn{7}{|c|}{ Lymph node metastasis } \\
\hline No & 516 & 420 & 465 & 0.003 & -0.056 & 0.064 \\
\hline Yes & 568 & 118 & 81 & & & \\
\hline \multicolumn{7}{|c|}{ Distant metastasis } \\
\hline No & 964 & 464 & 450 & 0.233 & -0.044 & 0.170 \\
\hline Yes & 22 & 14 & 8 & & & \\
\hline \multicolumn{7}{|c|}{ Clinical stage } \\
\hline 1 & 183 & 80 & 103 & 0.058 & -0.084 & 0.006 \\
\hline II--IV & 899 & 462 & 437 & & & \\
\hline
\end{tabular}

we attempted to analyze the association of ZNF132 expression with patient clinicopathological features using TCGA dataset. Chi-square test showed that the expression of ZNF132 was significantly associated with HER2 status $(P=0.001)$, ER status $(P=0.000)$, PR status $(\mathrm{P}=0.000)$, tumor size $(P=0.006)$ and lymph node metastasis $(P=0.003)$ (Table 1$)$.

\section{ZNF132 was a prognostic factor and diagnostic marker in $\mathrm{BC}$}

The result from the Kaplan-Meier plotter revealed that low ZNF132 expression was significantly associated with a shorter RFS time in BC(Fig. 2,a $p=2.3 \mathrm{E}$ 14)Univariate COX regression analysis confirmed that some clinical features including age, tumor size, lymph node metastasis, distant metastasis and clinical stage were significantly associated with $\mathrm{OS}$ in $\mathrm{BC}$ patients (Table2). However, there was no statistical significance between the expression of ZNF132 and the prognosis of $\mathrm{BC}(\mathrm{HR}=1.129, P=0.587)$ using multivariate analysis (Table3). Moreover, an area under the curve (AUC, representing the accuracy of differentiation) of 0.887 suggested that the level of ZNF132 has sufficient sensitivity and specificity to identify the difference between $\mathrm{BC}$ and adjacent normal tissues (Fig. 2b).

\section{Bioinformatic analysis of ZNF132}

The result from cBioPortal revealed that 6\% (58/960) of BC exhibited ZNF132 alteration including missense mutation (2/960), amplification (19/960), deep

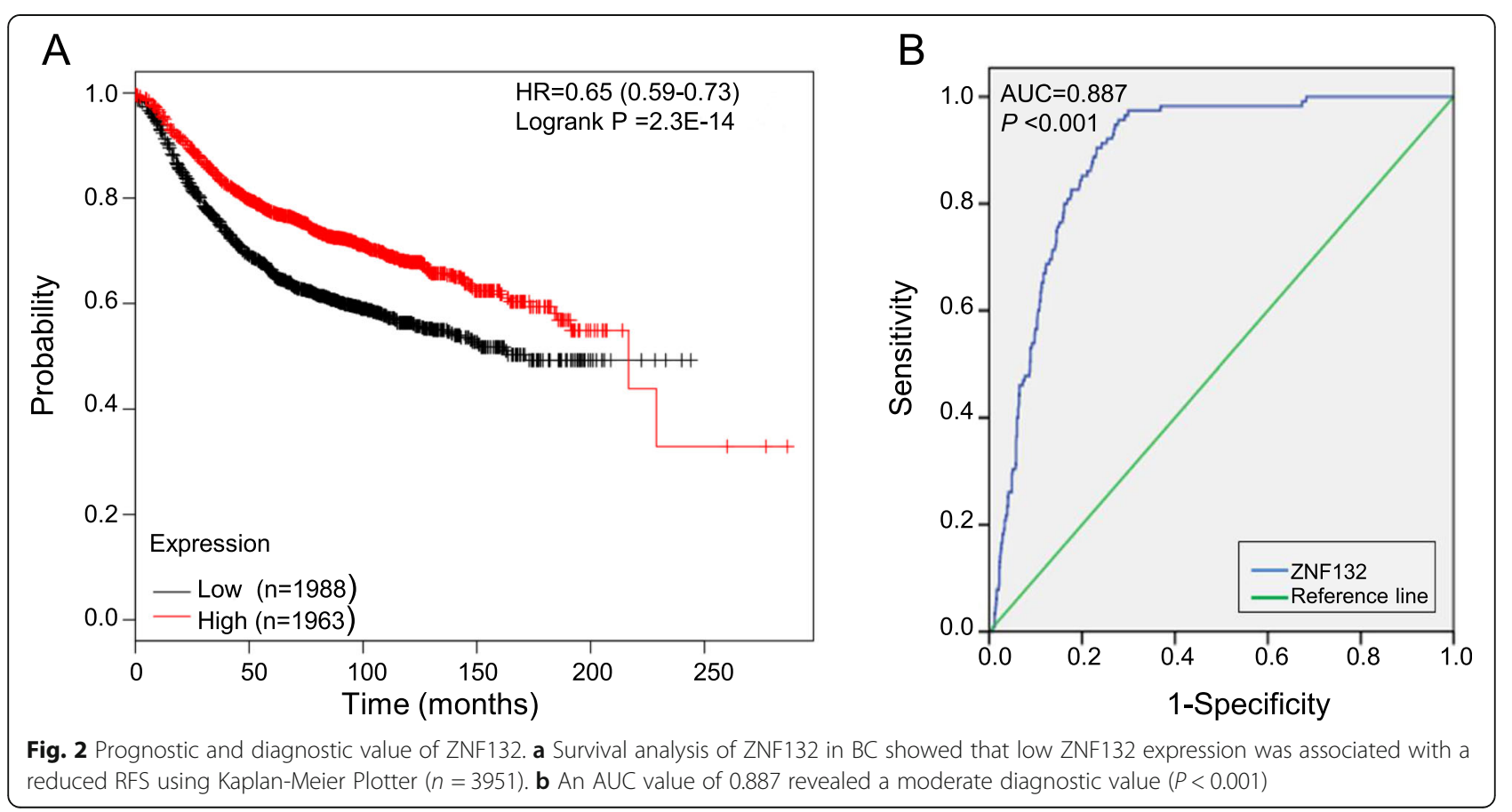


deletion (6/960), mRNA upregulation (13/960) and mRNA downregulation (18/960) (Fig. 3a). Prognosis analysis was performed to explore the influences with and without ZNF132 alteration. The result showed a statistically significant difference existed for OS but not for DFS (Fig. 3b). The analysis from GSEA showed that ZNF132 participated in mediating multiple biological processes including cilium organization, cilium or flagellum-dependent cell motility, synaptic transmission, glutamatergic, microtubule bundle formation, mitochondrial gene expression, mitochondrial respiratory chain complex assembly, ribonucleoprotein complex biogenesis, translational initiation etc. (Fig. 3c). The biological pathways of ZNF132 contained the regulation of cell cycle, glycolysis, cholesterol biosynthesis, ubiquitin proteasome pathway, TCA cycle (Fig. 3d). Cyclin E1 (CCNE1) and Alpha-enolase (ENO1) are located at the core position of the cell cycle and glycolysis regulation gene sets. The correlation analysis indicated

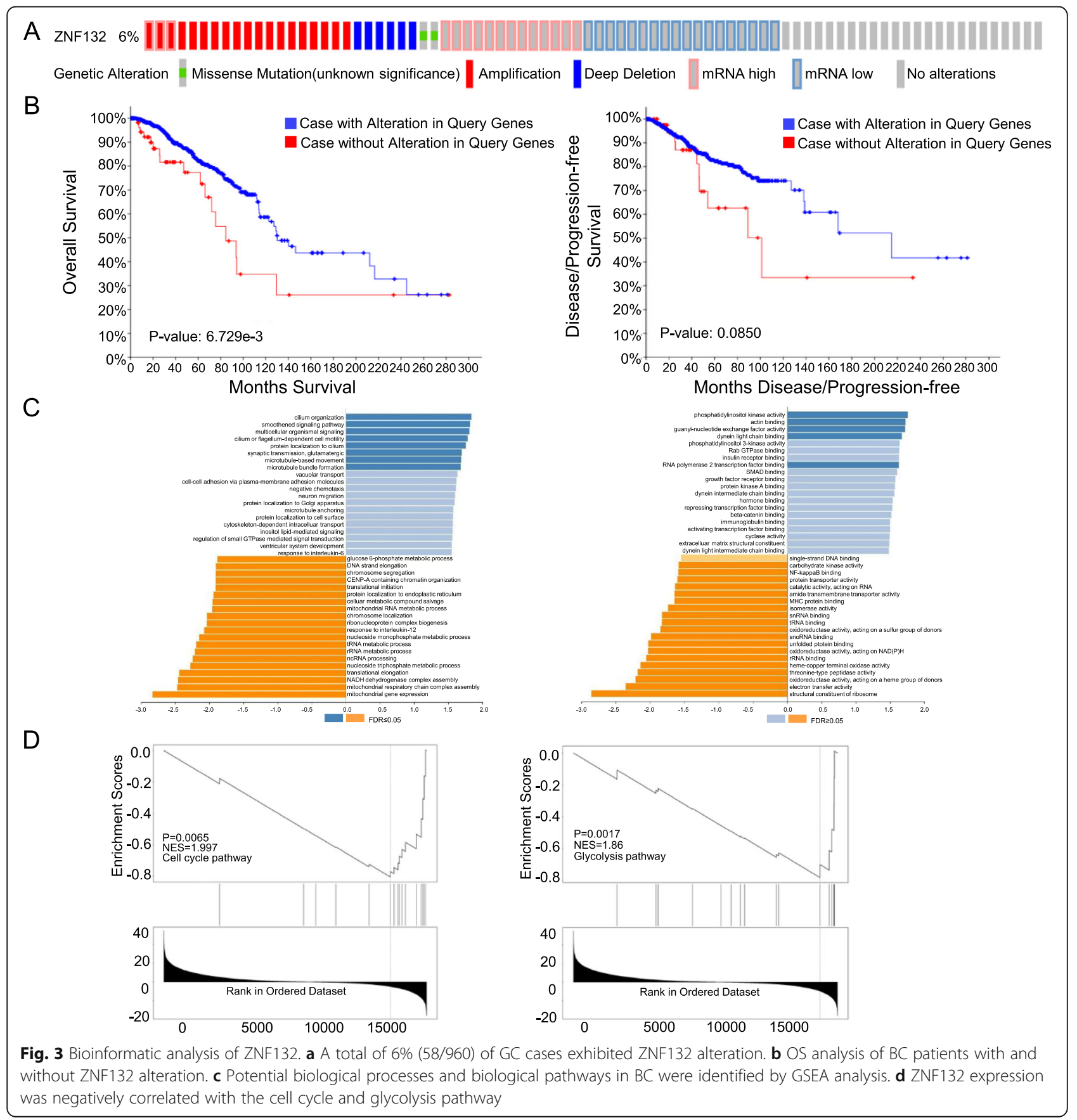


that ZNF132 expression was negatively associated with the cyclin E1(Fig. 4a)and ENO1 level (Fig. 4b).

\section{Hypermethylation of ZNF132 in BC}

Aberrant DNA methylation serves as an important mechanism for downregulation of gene expression and its process involves the cooperative effect among methyltransferases DNMT1, 3A and 3B. Firstly, the expression of DNMT1, DNMT3A and DNMT3B was analyzed in the BC tissues $(n=1104)$ using TCGA dataset. As shown in Fig. 5a, the 3 DNA methyltransferases showed higher expression in the ZNF132 $2^{\text {low }}$ group as compared to ZNF132 $2^{\text {high }}$ group. Result from MethHC [28] (http://methhc.mbc.nctu. edu.tw/php/index.php) also demonstrated that the methylation level of ZNF132 was significantly higher in $\mathrm{BC}$ tissues than the normal sample (Fig. 5b). The analysis of different $\mathrm{CpG}$ island methylation sites based on the TCGA database also revealed the same trend (Fig. 5c). The ZNF132 methylation level was negatively correlated with its gene expression (Fig. 5d). ZNF132 methylation was detected in a panel of breast cancer cell lines using MSP assay. As shown in Fig. 5f-g 5-Aza-dC could restore the mRNA and protein levels of ZNF132 in partial cell lines including MDA-MB-231, MCF7 and HCC1937 as compared to the untreated normal controls.

\section{ZNF132 methylation was correlated with prognosis and clinicopathological features of BC}

The investigation from MethSurv (https://biit.cs.ut.ee/ methsurv/) showed that BC patients with higher ZNF132 methylation had a shorter survival time (Fig. 6a; $P=1.802 \mathrm{E}-04$ ). Survival analyses of different methylated regions also demonstrated a similar trends (Fig. 6a; cg12042695, $P=0.00038 ; \operatorname{cg} 19776201, P=$ 0.041; cg24366702, $P=0.029$; $\operatorname{cg} 00868383, P=0.0023$; cg03735888, $P=0.00024)$. UALCAN was used to evaluate the impact of aberrant methylation on the clinicopathological features of $\mathrm{BC}$ patients. The analysis showed that high methylation levels of ZNF132 were associated with older age and advanced tumor stage in $\mathrm{BC}$ patients as compared to low methylation group. The same trend was obtained in Asian regions and male patients (Fig. 6b).

\section{Discussion}

Breast cancer is an aggressive malignant tumor in females. The common metastasis locations are: lungs, bone and brain. $\mathrm{BC}$ causes approximately 522,000 deaths yearly [1]. However, the specific mechanism of $B C$ is still unclear. Currently, the causes of BC involve many events including genetics and epigenetics modification. Epigenetic changes include DNA promoter methylation, gene mutation and deletion in tumorigenesis. In the past decades, DNA methylation has been demonstrated to be a promising early diagnostic biomarker for BC. However, useful markers in practice have not been completely identified.

Zinc finger protein is an important family of transcription factors. Majority of human zinc finger proteins contain the KRAB domains. KRAB domains has been proved to act as a transcriptional repressor by interacting with KAP1 and subsequently recruiting histone-modifying proteins $[21,29,30]$. ZNF132, a member of the zinc finger protein family, is only reported to be downregulated by promoter methylation in ECSC and PC [31, 32]. However, its diagnostic and prognostic values have not been elucidated in BC until now. This study is the first one to systematically explore the clinical significance of ZNF132 in BC.

This paper indicates that ZNF132 has a significantly lower expression in $\mathrm{BC}$ tissues than adjacent normal
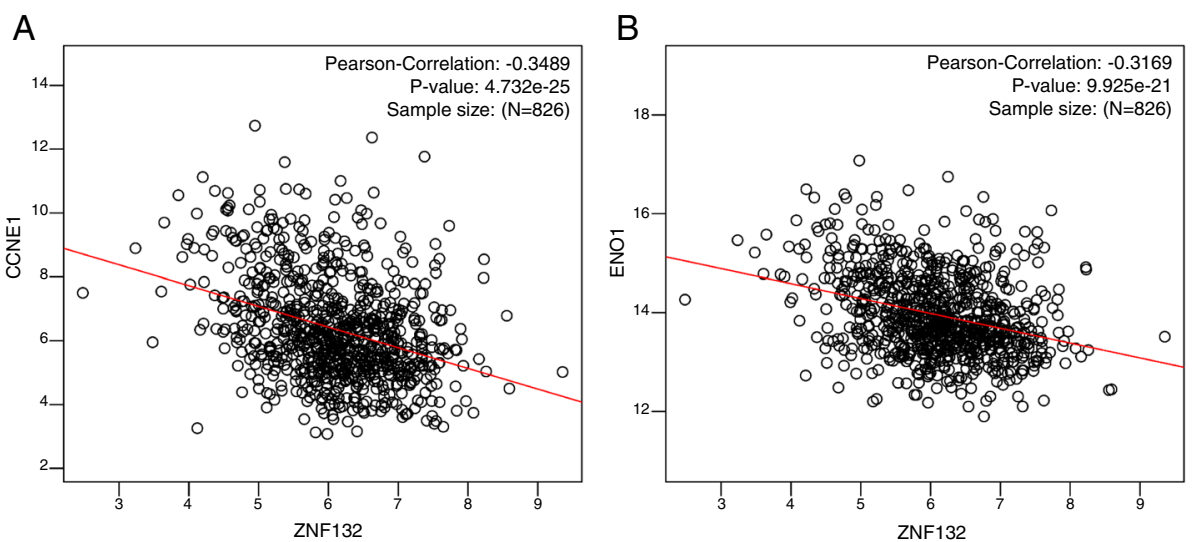

Fig. 4 Genes involved in the cell cycle and glycolysis were associated with ZNF132 expression. a ZNF132 was negatively correlated with the expression of CCNE1 in cell cycle and (b) the expression of ENO1 in glycolysis 


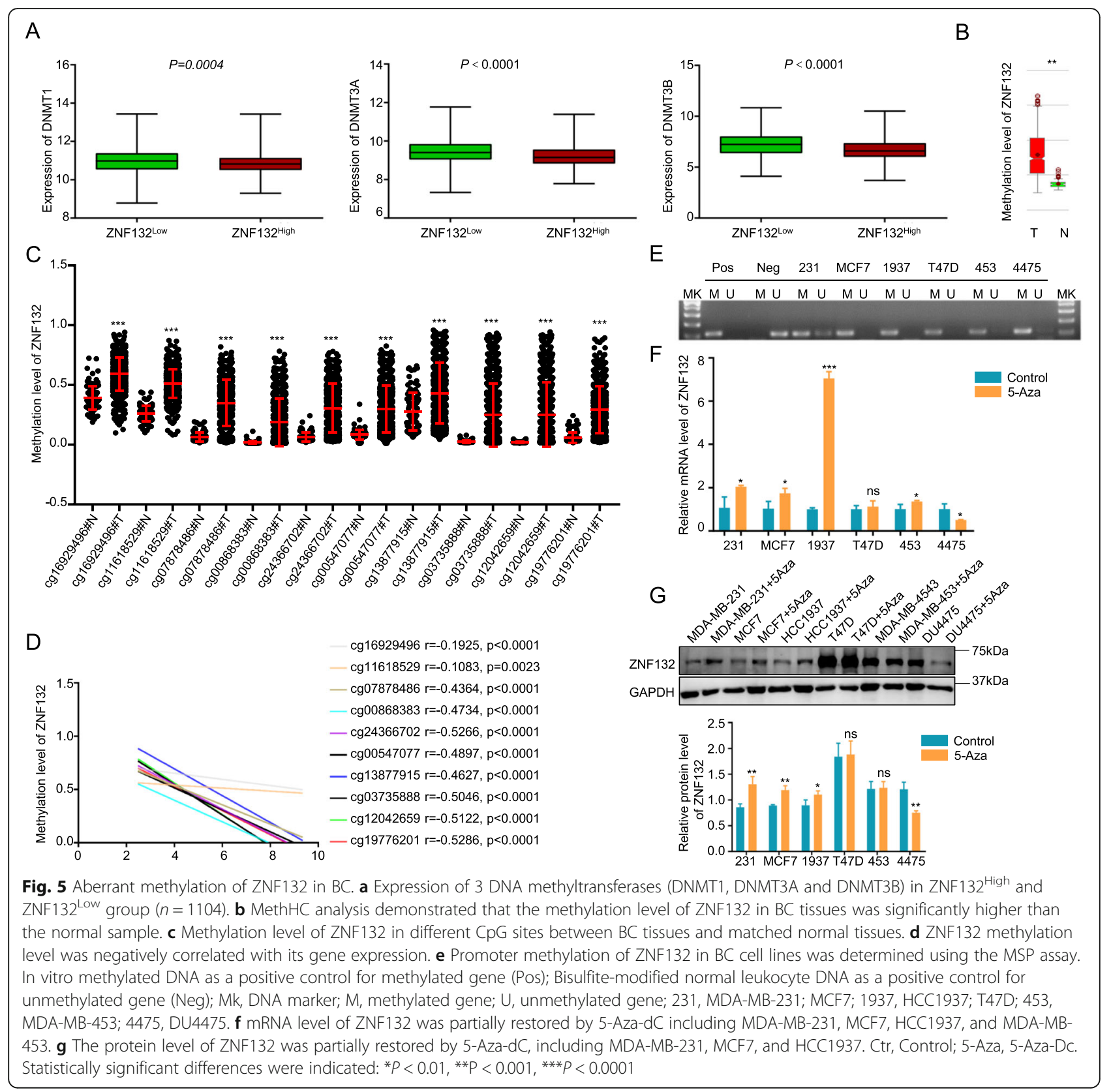

tissues both in mRNA and protein level. This implied that ZNF132 can serve as a tumor suppressor in BC. This was in agreement with the study of ZNF132 in ECSC and PC. Larger samples need to be collected to provide more powerful evidence to verify the role of ZNF132 in BC. In addition, the ROC curve revealed that ZNF132 displayed a significant diagnostic value for $\mathrm{BC}$ (AUC $=0.887, P<0.001$ ). Lower ZNF132 expression correlates with worse prognosis of $\mathrm{BC}$. ZNF132 cant be a promising diagnostic and prognostic marker for BC. However, as demonstrated in Table 2 and Table 3, univariate and multivariate analysis failed to provide independent prognostic information for ZNF132 expression. The possible reasons are summarized as follows: a). A series of mixed factors were involved in the prognosis of $\mathrm{BC}$. The common factors were only listed in the present study. b). Samples in this study based on the TCGA database were insufficient to clarify the correlation between ZNF132 expression and prognostic value. Therefore, large-scale prospective study would be necessary to confirm the value of ZNF132 in future. Moreover, analysis from Kaplan-Meier plotter revealed that low ZNF132 expression was associated with a shorter RFS for patients of BC but absent in OS. Therefore, ZNF132 expression can detect BC 


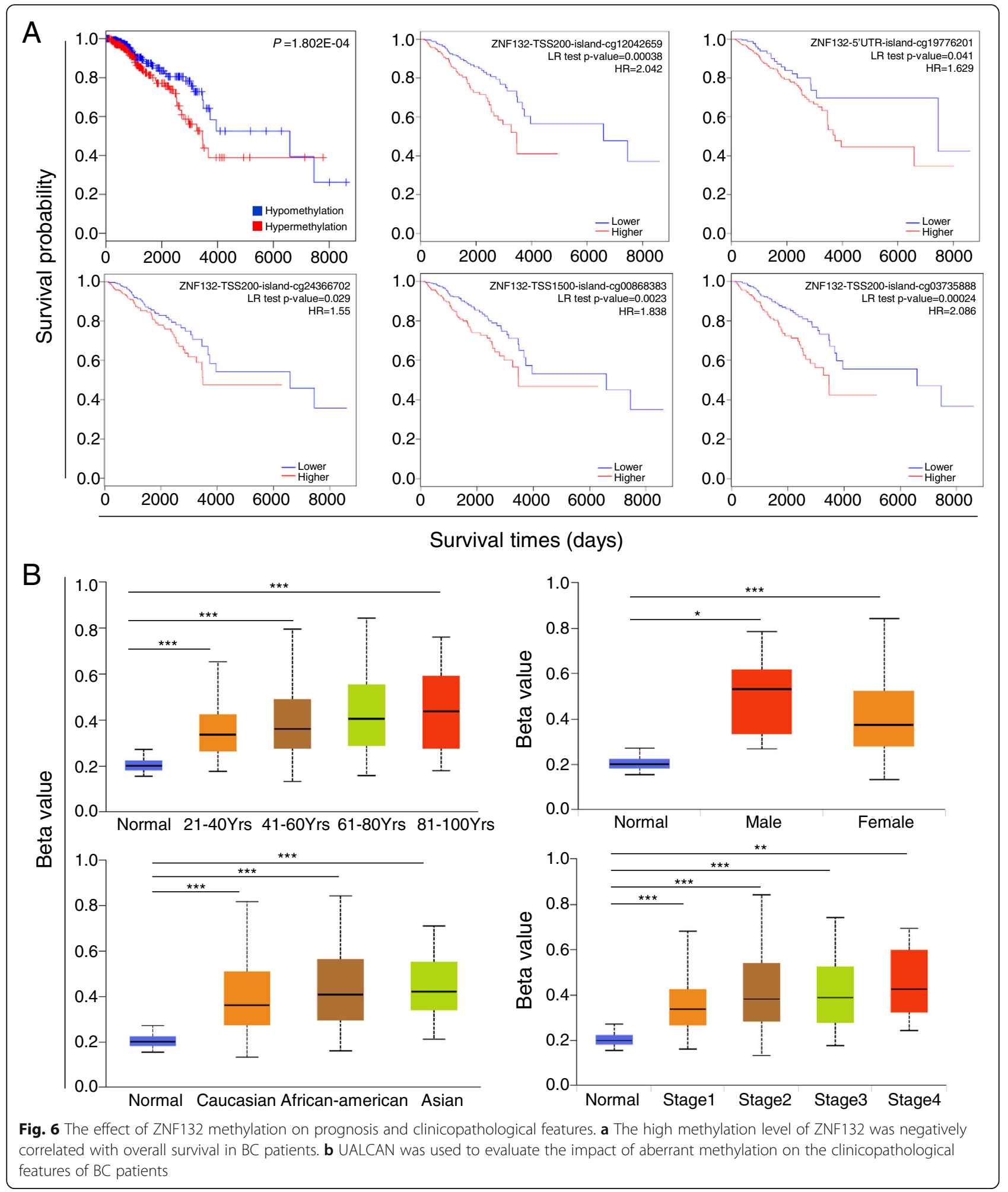

recurrence. Based on tumor heterogeneous characteristics, $\mathrm{BC}$ is classified according to several molecular subgroups: luminal A, luminal B, human epidermal growth factor receptor 2 (HER2), normal and basal-like based on immunohistochemical evaluation of estrogen receptor (ER), progesterone receptor (PR), HER2 and proliferation marker Ki-67. Analysis based on TCGA database revealed that downregulated ZNF132 was correlated with the malignant phenotype of $\mathrm{BC}$. This included positive 
Table 2 Univariate analysis of prognostic factors of BC

\begin{tabular}{llll}
\hline Variable & Hazard ratio & $\mathbf{9 5 \% C l}$ & $\boldsymbol{P}$-value \\
\hline Age(>60/_60) & 1.928 & $(1.402,2.652)$ & 0.000 \\
HER2(Positive / Negative) & 1.402 & $(0.592,1.834)$ & 0.886 \\
ER(Positive/Negative) & 1.018 & $(0.659,1.573)$ & 0.937 \\
PR(Positive/Negative) & 0.938 & $(0.637,1.379)$ & 0.744 \\
Tumor size(T2-T4/T1) & 1.500 & $(1.020,2.206)$ & 0.040 \\
Lymph Node metastasis(Yes/No) & 2.200 & $(1.542,3.140)$ & 0.000 \\
Distant metastasis(Yes/No) & 4.749 & $(2.840,7.940)$ & 0.000 \\
Clinical stage(II-IV/I) & 2.249 & $(1.337,3.783)$ & 0.002 \\
ZNF132 expression(High/Low) & 0.829 & $(0.602,1.143)$ & 0.252 \\
\hline
\end{tabular}

HER2 status, larger tumor sizes, distant metastasis and advanced clinical stage, indicating ZNF132 suppresses the progression of $\mathrm{BC}$ by inhibiting the growth, invasion, and metastasis of tumor cells. ZNF132 expression was positively associated with ER and PR status. Further investigation is needed to determine whether combined detection of ZNF132 together with other molecules would be valuable in improving prognosis assessment.

The first investigation from cBioPortal showed that approximately 6\% BC patients exhibited ZNF132 alterations. The mRNA downregulation was the predominant type of alteration. This could contribute to the downregulation of ZNF132 in BC. This helped recognize the potential mechanisms of ZNF132 in BC. In addition, the analysis based on GSEA demonstrated that ZNF132 participated in a variety of important biological processes and pathways. CCNE1 and ENO1 are located at an important position in these biological processes. Cyclin E1 (CCNE1) belongs to the highly conserved cyclin family and forms a complex with CDK2 whose activity is required for cell cycle G1/S transition. CCNE1 has been reported to upregulated in various human cancer including breast [33], bladder [34] and ovarian [35]. CCNE1 mediates premature S-phase entry, ineffective DNA replication and

Table 3 Multivariate analysis of prognostic factors of BC

\begin{tabular}{llll}
\hline Variable & Hazard ratio & $\mathbf{9 5 \% C l}$ & $\boldsymbol{P}$-value \\
\hline Age(>60/_60) & 2.278 & $(1.453,3.571)$ & 0.000 \\
HER2(Positive / Negative) & 0.804 & $(0.405,1.597)$ & 0.533 \\
ER(Positive/Negative) & 1.015 & $(0.507,2.032)$ & 0.966 \\
PR(Positive/Negative) & 0.618 & $(0.330,1.154)$ & 0.131 \\
Tumor size(T2-T4/T1) & 1.238 & $(0.548,2.800)$ & 0.608 \\
Lymph Node metastasis(Yes/No) & 1.630 & $(0.959,2.770)$ & 0.071 \\
Distant metastasis(Yes/No) & 3.427 & $(1.665,7.055)$ & 0.001 \\
Clinical stage(II-IV/I) & 1.140 & $(0.386,3.369)$ & 0.813 \\
ZNF132 expression(High/Low) & 1.129 & $(0.728,1.753)$ & 0.587 \\
\hline
\end{tabular}

genomic instability. Alpha-enolase (ENO1) is a prominent glycolytic enzyme. ENO1 was upregulated in multiple cancers and its overexpression was involved in tumor cell proliferation and metastasis such as glioma [36], gastric [37], pancreatic [38], colorectal [39], BC [40] etc. ZNF132 expression was negatively associated with CCNE1 and ENO1 level based on the correlation analysis. Therefore ZNF132 might inhibit the progression of $\mathrm{BC}$ by regulating the expression of ENO1 and CCNE1.

Aberrant promoter methylation permanently inactivate tumor-associated genes, particularly tumor suppressor genes [41]. In this study, ZNF132 methylation level was higher in $\mathrm{BC}$ tissue than that in normal tissues. Moreover, 3 DNA methyltransferases were overexpressed in the ZNF132 $2^{\text {low }}$ group. Methylated modification of ZNF132 was detected in $6 \mathrm{BC}$ cell lines. 5-Aza-dC treatment restores the mRNA and protein levels of ZNF132 in some cell lines including MDA-MB-231, MCF7 and HCC1937. However, 5Aza-dC failed to restore the expression of ZNF132 between the mRNA and protein levels in the T47D cell. Besides, the MDA-MB-453 cell failed to restore ZNF132 expression at the protein level. Moreover, an opposite trend was obtained in DU4475. The most likely reason is that the ZNF132 gene may undergo other epigenetic modifications including transcription and post-transcriptional regulation. Finally, methylation analysis in $10 \mathrm{CpG}$ island sites including cg169294963, cg11618529, cg07878486, cg00868383, cg24366702, cg00547077, cg13877915, cg03735888, cg12042659 and cg19776201 indicated that these sites were hypermethylated in BC sample. This suggested that DNA methylation in these sites inactivates ZNF132 gene transcription. Clinical samples analysis provided strong evidence between promoter methylation status and expression of ZNF132 in BC. Therefore, ZNF132 hypermethylation act as an independent risk factor in $\mathrm{BC}$ patients.

\section{Conclusion}

In conclusion, this research demonstrated the expression, diagnostic ability and prognostic significance of ZNF132 based on the TCGA database. Aberrant hypermethylation of ZNF132 mediated its silence in BC. Therefore, ZNF132 could be used as a potential target for diagnosis and prognostic evaluation in BC.

\footnotetext{
Abbreviations

TCGA: The Cancer Genome Atlas; ZNF132: Zinc Finger Protein 132; AUC: An area under the curve; ROC: Receiver operating characteristic curve;

OS: Overall survival; RFS: Relapse-free survival; DFS: Disease-free survival; BC: Breast cancer; GSEA: Gene Set Enrichment Analysis; MSP: Methylationspecific PCR
} 


\section{Supplementary Information}

The online version contains supplementary material available at https://doi. org/10.1186/s12885-021-08112-z.

Additional file 1: Supplement Fig.5E. Original gel image. Additional file 2: Supplement Fig.1F \& Fig.5G. Original blots image.

Acknowledgments

Not applicable.

\section{Authors' contributions}

All authors have read and approved the manuscript. $Z \mathrm{~L}, \mathrm{~J}$ and $\mathrm{PX}$ conceived and designed the experiments; RML, WFZ and XHZ performed the experiments; MX and JZ analyzed the data. In addition, PX provided BC specimens, as well as giving final approval of the version to be published.

\section{Funding}

This study was supported by the Open Project Program of Key Laboratory for Tumor Precision Medicine of Shaanxi Province, First Affiliated Hospital of Xi'an Jiaotong University, People's Republic of China (KLTPM-SX2024-C1). The funding body was mainly involved in the design of the study and data analysis.

\section{Availability of data and materials}

The datasets used and analyzed during the current study are available from TCGA database (http://cancergenome.nih.gov/) and multiple online tools, including Oncomine ${ }^{T M}$ database (www.oncomine.org), UALCAN platform (http://ualcan.path. uab.edu/) and Xena platform (https://xenabrowser.net/).

\section{Declarations}

\section{Ethics approval and consent to participate}

The present study was approved by the First Affiliated Hospital of Xi'an Jiaotong University Ethics committee. Written informed consent was obtained from all patients.

\section{Consent for publication}

All patients consented to the publication of data and any associated images.

\section{Competing interests}

All authors and funding body declared that they had no competing interest.

\section{Author details}

${ }^{1}$ Department of Surgical Oncology, The First Affiliated Hospital of Xi'an Jiaotong University College of Medicine, Xi'an 710061, Shaanxi, China. ${ }^{2}$ Department of Gerontological Surgery, The First Affiliated Hospital of Xi'an Jiaotong University College of Medicine, Xi'an 710061, Shaanxi, China. ${ }^{3}$ Department of Clinical Laboratory, Peoples Hospital of Xi'an (Fourth Hospital of Xi'an), Xi'an 710004, Shaanxi, China. ${ }^{4}$ Department of General Surgery, Tongchuan Mining Bureau Central Hospital, Tongchuan 727000, Shaanxi, China. ${ }^{5}$ Department of Breast Disease, Shaanxi Provincial Cancer Hospital, Xi'an 710061, Shaanxi, China.

Received: 10 September 2019 Accepted: 28 March 2021

Published online: 07 April 2021

\section{References}

1. Ferlay J, Soerjomataram I, Dikshit R, Eser S, Mathers C, Rebelo M, et al. Cancer incidence and mortality worldwide: sources, methods and major patterns in GLOBOCAN 2012. Int J Cancer. 2015;136(5):E359-86. https://doi. org/10.1002/ijc.29210.

2. DeSantis C, Ma J, Bryan L, Jemal A. Breast cancer statistics, 2013. CA Cancer J Clin. 2014;64(1):52-62. https://doi.org/10.3322/caac.21203.

3. Kolacinska A, Herman K, Morawiec J, Paszek S, Zawlik I, Sliwczynski A. Improvement in outcomes of breast cancer patient treatment in Poland in the 21st century. Breast J. 2019;25(3):474-8. https://doi.org/10.1111/ tbj.13245.

4. Koroukian SM, Bakaki PM, Htoo PT, Han X, Schluchter M, Owusu C, et al. The breast and cervical Cancer early detection program, Medicaid, and breast cancer outcomes among Ohio's underserved women. Cancer. 2017;123(16): 3097-106. https://doi.org/10.1002/cncr.30720.

5. Howard DH, Tangka FK, Royalty J, Dalzell LP, Miller J, O'Hara B, et al. Breast cancer screening of underserved women in the USA: results from the National Breast and cervical Cancer early detection program, 1998-2012. Cancer Causes Control : CCC. 2015;26(5):657-68. https://doi.org/10.1007/s1 0552-015-0553-0.

6. Miller JW, Hanson V, Johnson GD, Royalty JE, Richardson LC. From cancer screening to treatment: service delivery and referral in the National Breast and cervical Cancer early detection program. Cancer. 2014;120(Suppl 16): 2549-56. https://doi.org/10.1002/cncr.28823.

7. Miller JW, Plescia M, Ekwueme DU. Public health national approach to reducing breast and cervical cancer disparities. Cancer. 2014;120(Suppl 16): 2537-9. https://doi.org/10.1002/cncr.28818.

8. Plescia M, Wong F, Pieters J, Joseph D. The National Breast and cervical Cancer early detection program in the era of health reform: a vision forward. Cancer. 2014;120(Suppl 16):2620-4. https://doi.org/10.1002/ cncr.28826.

9. Siegel RL, Miller KD, Jemal A. Cancer statistics, 2018. CA Cancer J Clin. 2018; 68(1):7-30. https://doi.org/10.3322/caac.21442.

10. Howlader NNAKM, Neyman N, Aminou R, Waldron W, Altekruse SF, Kosary CL, et al. SEER cancer statistics review, 1975-2008. Bethesda: National Cancer Institute; 2011.

11. Gyorffy B, Bottai G, Fleischer T, Munkacsy G, Budczies J, Paladini L, et al. Aberrant DNA methylation impacts gene expression and prognosis in breast cancer subtypes. Int J Cancer. 2016;138(1):87-97. https://doi.org/10.1 002/ijc.29684.

12. Jovanovic J, Ronneberg JA, Tost J, Kristensen V. The epigenetics of breast cancer. Mol Oncol. 2010;4(3):242-54. https://doi.org/10.1016/j. molonc.2010.04.002.

13. Polyak K. Breast cancer: origins and evolution. J Clin Invest. 2007;117(11): 3155-63. https://doi.org/10.1172/JCl33295.

14. Rodriguez-Paredes M, Esteller M. Cancer epigenetics reaches mainstream oncology. Nat Med. 2011;17(3):330-9. https://doi.org/10.1038/nm.2305.

15. Tapia T, Smalley SV, Kohen P, Munoz A, Solis LM, Corvalan A, et al. Promoter hypermethylation of BRCA1 correlates with absence of expression in hereditary breast cancer tumors. Epigenetics. 2008;3(3):157-63. https://doi. org/10.4161/epi.3.3.6387.

16. Esteller M, Corn PG, Baylin SB, Herman JG. A gene hypermethylation profile of human cancer. Cancer Res. 2001;61(8):3225-9.

17. Widschwendter $M$, Jones PA. DNA methylation and breast carcinogenesis. Oncogene. 2002;21(35):5462-82. https://doi.org/10.1038/sj.onc.1205606.

18. Wittenberger T, Sleigh S, Reisel D, Zikan M, Wahl B, Alunni-Fabbroni M, et al. DNA methylation markers for early detection of women's cancer: promise and challenges. Epigenomics. 2014;6(3):311-27. https://doi.org/10.2217/ epi.14.20.

19. Raffel S, Falcone M, Kneisel N, Hansson J, Wang W, Lutz C, et al. BCAT1 restricts aKG levels in AML stem cells leading to IDHmut-like DNA hypermethylation. Nature. 2017;551(7680):384-8. https://doi.org/10.1038/na ture24294.

20. Jen J, Wang YC. Zinc finger proteins in cancer progression. J Biomed Sci. 2016;23(1):53. https://doi.org/10.1186/s12929-016-0269-9.

21. Fedotova AA, Bonchuk AN, Mogila VA, Georgiev PG. C2H2 zinc finger proteins: the largest but poorly explored family of higher eukaryotic transcription factors. Acta Nat. 2017;9(2):47-58. https://doi.org/10.32607/2 0758251-2017-9-2-47-58.

22. Tomczak K, Czerwińska P, Wiznerowicz M. The Cancer Genome Atlas (TCGA): an immeasurable source of knowledge. Contemporary oncology (Poznan, Poland), 2015. 19(1a):A68-77.

23. Rhodes DR, Yu J, Shanker K, Deshpande N, Varambally R, Ghosh D, et al. ONCOMINE: a cancer microarray database and integrated data-mining platform. Neoplasia (New York, NY). 2004;6(1):1-6.

24. Chandrashekar DS, Bashel B, Balasubramanya SAH, Creighton CJ, PonceRodriguez I, Chakravarthi B, et al. UALCAN: A Portal for Facilitating Tumor Subgroup Gene Expression and Survival Analyses. Neoplasia (New York, NY). 2017:19(8):649-58

25. Rio DC, Ares M Jr, Hannon GJ, Nilsen TW. Purification of RNA using TRIzol (TRI reagent). Cold Spring Harbor protocols. 2010;2010(6):pdb.prot5439.

26. Vasaikar SV, Straub P, Wang J, Zhang B. LinkedOmics: analyzing multi-omics data within and across 32 cancer types. Nucleic Acids Res. 2018;46(D1): D956-d963. https://doi.org/10.1093/nar/gkx1090. 
27. Modhukur V, lljasenko T, Metsalu T, Lokk K, Laisk-Podar T, Vilo J. MethSurv: a web tool to perform multivariable survival analysis using DNA methylation data. Epigenomics. 2018;10(3):277-88. https://doi.org/10.2217/epi-2017-0118.

28. Huang WY, Hsu SD, Huang HY, Sun YM, Chou CH, Weng SL, et al. MethHC: a database of DNA methylation and gene expression in human cancer. Nucleic Acids Res. 2015;43(Database issue):D856-61. https://doi.org/10.1093/ nar/gku1151.

29. Margolin JF, Friedman JR, Meyer WK, Vissing H, Thiesen HJ, Rauscher FJ 3rd. Krüppel-associated boxes are potent transcriptional repression domains. Proc Natl Acad Sci U S A. 1994;91(10):4509-13. https://doi.org/10.1073/pnas. 91.10.4509.

30. Vissing H, Meyer WK, Aagaard L, Tommerup N, Thiesen HJ. Repression of transcriptional activity by heterologous KRAB domains present in zinc finger proteins. FEBS Lett. 1995;369(2-3):153-7. https://doi.org/10.1016/0014-5793 (95)00728-R.

31. Jiang D, He Z, Wang C, Zhou Y, Li F, Pu W, et al. Epigenetic silencing of ZNF132 mediated by methylation-sensitive Sp1 binding promotes cancer progression in esophageal squamous cell carcinoma. Cell Death Dis. 2018; 10(1):1. https://doi.org/10.1038/s41419-018-1236-z.

32. Abildgaard MO, Borre M, Mortensen MM, Ulhoi BP, Torring N, Wild P, et al. Downregulation of zinc finger protein 132 in prostate cancer is associated with aberrant promoter hypermethylation and poor prognosis. Int I Cancer. 2012;130(4):885-95. https://doi.org/10.1002/ijc.26097.

33. Zhao ZM, Yost SE, Hutchinson KE, Li SM, Yuan YC, Noorbakhsh J, et al. CCNE1 amplification is associated with poor prognosis in patients with triple negative breast cancer. BMC Cancer. 2019;19(1):96. https://doi.org/1 0.1186/s12885-019-5290-4.

34. Matsushita R, Seki N, Chiyomaru T, Inoguchi S, Ishihara T, Goto Y, et al. Tumour-suppressive microRNA-144-5p directly targets CCNE1/2 as potential prognostic markers in bladder cancer. Br J Cancer. 2015;113(2):282-9. https://doi.org/10.1038/bjc.2015.195.

35. Nakayama N, Nakayama K, Shamima Y, Ishikawa M, Katagiri A, lida K, et al. Gene amplification CCNE1 is related to poor survival and potential therapeutic target in ovarian cancer. Cancer. 2010;1 16(11):2621-34. https:// doi.org/10.1002/cncr.24987.

36. Song Y, Luo Q, Long H, Hu Z, Que T, Zhang X, et al. Alpha-enolase as a potential cancer prognostic marker promotes cell growth, migration, and invasion in glioma. Mol Cancer. 2014;13(1):65. https://doi.org/10.1186/1476-4 598-13-65.

37. Sun L, Lu T, Tian K, Zhou D, Yuan J, Wang X, et al. Alpha-enolase promotes gastric cancer cell proliferation and metastasis via regulating AKT signaling pathway. Eur J Pharmacol. 2019;845:8-15. https://doi.org/10.1016/j.ejphar.2 018.12.035.

38. Shen J, Person MD, Zhu J, Abbruzzese JL, Li D. Protein expression profiles in pancreatic adenocarcinoma compared with normal pancreatic tissue and tissue affected by pancreatitis as detected by two-dimensional gel electrophoresis and mass spectrometry. Cancer Res. 2004;64(24):9018-26. https://doi.org/10.1158/0008-5472.CAN-04-3262.

39. Zhan P, Zhao S, Yan H, Yin C, Xiao Y, Wang Y, et al. Alpha-enolase promotes tumorigenesis and metastasis via regulating AMPK/MTOR pathway in colorectal cancer. Mol Carcinog. 2017;56(5):1427-37. https://doi.org/10.1002/ mc.22603.

40. Tu SH, Chang CC, Chen CS, Tam KW, Wang YJ, Lee CH, et al. Increased expression of enolase alpha in human breast cancer confers tamoxifen resistance in human breast cancer cells. Breast Cancer Res Treat. 2010;121(3): 539-53. https://doi.org/10.1007/s10549-009-0492-0.

41. Shi J, Liu W, Sui F, Lu R, He Q, Yang Q, et al. Frequent amplification of AIB1, a critical oncogene modulating major signaling pathways, is associated with poor survival in gastric cancer. Oncotarget. 2015;6(16):14344-59. https://doi. org/10.18632/oncotarget.3852.

\section{Publisher's Note}

Springer Nature remains neutral with regard to jurisdictional claims in published maps and institutional affiliations.

Ready to submit your research? Choose BMC and benefit from:

- fast, convenient online submission

- thorough peer review by experienced researchers in your field

- rapid publication on acceptance

- support for research data, including large and complex data types

- gold Open Access which fosters wider collaboration and increased citations

- maximum visibility for your research: over $100 \mathrm{M}$ website views per year

At BMC, research is always in progress.

Learn more biomedcentral.com/submissions 